\title{
COMMENTARY
}

\section{The therapeutic potential of a venomous lizard: the use of glucagon-like peptide- 1 analogues in the critically ill}

\author{
Adam M Deane* ${ }^{* 1,2,3}$, Marianne J Chapman 1,2,3 and Michael Horowitz ${ }^{3,4}$ \\ See related research by Mecott et al., http://ccforum.com/content/14/4/R153
}

\begin{abstract}
Glucagon-like peptide-1 (GLP-1), a principal mediator of the postprandial insulinotropic response in health, has a half-life of minutes. The saliva of the Gila monster contains exendin-4, a structural analogue of human GLP-1, but with a much longer half-life. A synthetic preparation of exendin-4, exenatide, is suitable for human use and effectively lowers glucose in ambulant type 2 diabetic patients. When compared with insulin, exenatide therapy is associated with a reduction in hypoglycaemic episodes and postprandial glycaemic excursions in this group. Accordingly, GLP-1 analogues are appealing therapies for hyperglycaemia in the critically ill patient and warrant further study.
\end{abstract}

In the previous issue of Critical Care Mecott and colleagues report the effects of a glucagon-like peptide-1 (GLP-1) analogue, exenatide, on glycaemia in severely burned paediatric patients [1]. The incretin hormones, GLP-1 and glucose-dependent polypeptide (GIP), mediate $70 \%$ of the insulin response to a meal [2]. While GIP is potently insulinotropic in health, its effect is markedly attenuated in type 2 diabetic patients, such that even pharmacological doses have little effect on glycaemia [3]. In contrast, physiological replacement or pharmacological administration of GLP-1 lowers glycaemia substantially in this group [3]. Accordingly, studies in ambulant type 2 diabetic patients have focused on the therapeutic potential administration of GLP-1 rather than GIP. Significantly, the glucose-lowering effects of

${ }^{*}$ Correspondence: adam.deane@adelaide.edu.au

'Discipline of Acute Care Medicine, University of Adelaide, North Terrace, Adelaide, South Australia, Australia 5000

Full list of author information is available at the end of the article exogenous GLP-1 are glucose dependent, such that even pharmacological doses of GLP-1 are most unlikely to cause hypoglycaemia.

Native GLP-1 is not used as a glucose-lowering agent in ambulant type 2 diabetic patients because of the necessity for continuous administration [4]. Endogenous GLP-1 is metabolised rapidly to its so-called inactive metabolite by the ubiquitous enzyme dipeptyl-peptidase-4 (DPP-4), the half-life of native GLP-1 being 1 to 2 minutes [5]. While this factor essentially precludes the use of exogenous GLP-1 in ambulant patients, rapid metabolism of an agent may be a desirable pharmacokinetic property in the hospitalised patient. Accordingly, our group and others have explored the effects of exogenous GLP-1 in a variety of hospitalised, adult patients [6-10].

Using a prospective, randomised, open-label, design, Mecott and colleagues compared an intervention (exenatide \pm insulin) with a control (intensive insulin therapy) in patients receiving small intestinal nutrient. The authors report that the intervention decreased insulin requirements while comparable glycaemic control was achieved. The therapeutic use of GLP-1 in critically ill patients is inherently attractive as it does not substantially increase the risk of hypoglycaemia [11]. In addition, GLP-1 therapies show reduced glycaemic variability when compared with insulin in ambulant diabetic patients [11].

Strengths of the study are the evaluation of a GLP-1based therapy in a new population (paediatric) that has suffered a specific insult (burns), and the prolonged duration of evaluation (up to 28 days). Finally, and perhaps most significantly, the investigators have elected to use a GLP-1 analogue (exenatide) rather than the synthetic peptide. The major advantages of exenatide when compared with GLP-1 are that it can be administered intermittently, as well as its cheaper price and ready availability (Table 1).

Limitations of the study, which are largely acknowledged by the authors, include its open-label design and 
Table 1. Comparison between GLP-1, GLP-1 analogues and DPP-4 inhibitors

\begin{tabular}{llll}
\hline & GLP-1 & GLP-1 analogues & DPP-4 inhibitors \\
\hline Name(s) & GLP-1-(7-36)NH & Sitagliptin \\
& & Vxenatide & Vildagliptin \\
& & Liraglutide & Saxagliptin \\
Administration & Intravenous & Subcutaneous & Oral \\
Studied in the critically ill patient & Yes & Yes & No \\
Current cost & Prohibitive & Expensive & Expensive \\
Availability & Limited & Yes & Yes \\
Half-life & 1 to 2 minutes & 2 to 15 hours & 2 to 14 hours \\
Additional effects mediated via inactive GLP-1 & Yes & No & No \\
Nausea & Yes & Yes & No \\
Weight & Loss & Loss & Weight neutral \\
Gastric emptying & Slows & Slows & Minimal, if any, effect \\
\hline
\end{tabular}

DPP-4, dipeptyl-peptidase-4; GLP-1, glucagon-like peptide-1.

the relatively small number of subjects studied, with the consequent potential for type 2 errors. The authors reported that the use of the GLP-1 analogue failed to reduce hypoglycaemic episodes and glycaemic variability. However, the lack of effect on variability and hypoglycaemia may reflect administration of exenatide \pm insulin, rather than using exenatide as a single agent. Plasma exenatide concentrations were not reported, and it should be recognised that concentrations may not be predictable in these subjects - since, even in healthy subjects, exenatide has a biological half-life of $\sim 3$ hours and large fluctuations in plasma levels occur with twicedaily subcutaneous administration. Furthermore, given the limited information on the mechanisms of glucoselowering in the critically ill patient, measurement of insulin and/or C-peptide, as well as glucagon, would have been valuable.

Exendin-4 was isolated originally from the saliva of the Gila monster (Heloderma suspectum), a slow-moving venomous lizard native to the United States and Mexico. The Gila monster eats only 5 to 10 times per year and a meal causes a substantial postprandial increase in plasma exendin-4 concentrations [12]. Exendin-4 shares 50\% amino acid sequence identity with human GLP-1 and binds to the pancreatic GLP-1 receptor in vitro. Importantly, exendin-4 is resistant to DPP-4 inactivation, thereby having a prolonged duration of action [12]. Exenatide, a synthetic form of exendin-4, has been shown to reduce fasting and postprandial glucose via glucosedependent stimulation of insulin and suppression of glucagon secretion, as well as slowing gastric emptying [13]. The latter is probably the dominant mechanism to account for glucose lowering after oral or intragastric meals in healthy subjects, type 2 diabetic patients, and those critically ill patients in whom gastric emptying is normal $[10,13]$. GLP-1 analogues with half-lives between 12 hours and 3 to 4 days have been recently developed. These analogues have less variation in plasma concentrations after once-daily (for example, liraglutide) or weekly (sustained release exenatide) administration than twice a day dosing (exenatide). Oral drugs that inactivate the DPP-4 enzyme (DPP-4 inhibitors) - thereby attenuating metabolism and increasing the availability of endogenous GLP-1 and GIP - have also entered the clinical domain (Table 1).

In the study of Mecott and colleagues, exenetide was well tolerated; but given the adverse effects associated with its use in ambulant diabetic patients, ongoing vigilance is warranted. These adverse effects include nausea and vomiting (usually transient) [14], as well as modest weight loss that occurs, and is frequently desirable, in ambulant type 2 diabetic patients [14], but may be detrimental in the critically ill patient. The potential association between GLP-1 analogues and pancreatitis remains uncertain [14]. Lastly, the investigators did not measure anti-exenatide antibodies or plasma calcitonin concentrations, but the significance of anti-exenatide antibiodies or mild increases in calcitonin concentrations is unclear [14].

Albeit preliminary, the present study represents part of a growing interest in the use of incretins, or incretin mimetics, for the management of hyperglycaemia in hospitalised patients [15]. The desirable blood glucose range in this group remains contentious, but, as with recent studies in ambulant type 2 diabetic patients, there seems to be minimal, or no, advantage in targeting glycaemia at the lower end of the fasting normal range. Rather, the latter may well be deleterious [16]. Because the glucose-lowering effect of GLP-1 is glucose dependent, there is likely to be a threshold - perhaps 
about 7 to $8 \mathrm{mmol} / \mathrm{l}$ - beyond which further reductions will only occur if exogenous insulin is co-administered. In addition to identifying the optimal glycaemic range, future studies should focus on the following: which of the incretin agents is most useful in the critically ill patient; whether these agents should be used in combination with insulin, or as single-agent therapy; and identification of the patient group most likely to benefit from administration of incretin mimetics.

\section{Abbreviations}

DPP-4, dipeptyl-peptidase-4; GIP, glucose-dependent polypeptide; GLP-1, glucagon-like peptide-1.

\section{Competing interests}

The authors declare that they have no competing interests.

\section{Author details}

'Discipline of Acute Care Medicine, University of Adelaide, North Terrace, Adelaide, South Australia, Australia 5000. ${ }^{2}$ Intensive Care Unit, Level 4 Emergency Services Building, Royal Adelaide Hospital, North Terrace, Adelaide, South Australia, Australia 5000. ${ }^{3}$ National Health and Medical Research Council of Australia Centre for Clinical Research Excellence in Nutritional Physiology and Outcomes, Level 6, Eleanor Harrald Building, North Terrace, Adelaide, South Australia, Australia 5000. ${ }^{4}$ Discipline of Medicine, University of Adelaide, Royal Adelaide Hospital, Level 6 Eleanor Harrald Building, North Terrace Adelaide, South Australia, Australia 5000.

Published: 21 October 2010

\section{References}

1. Mecott GA, Herndon DN, Kulp GA, Brooks N, Al-Mousawi AM, Kraft R, Rivero HG, Williams FN, Branski LK, Jeschke MG: The use of exenatide in severely burned pediatric patients. Crit Care 2010, 14:R153.

2. Nauck MA, Homberger E, Siegel EG, Allen RC, Eaton RP, Ebert R, Creutzfeldt W: Incretin effects of increasing glucose loads in man calculated from venous insulin and C-peptide responses. J Clin Endocrinol Metab 1986, 63:492-498.

3. Nauck MA, Heimesaat MM, Orskov C, Holst JJ, Ebert R, Creutzfeldt W: Preserved incretin activity of glucagon-like peptide 1 [7-36 amide] but not of synthetic human gastric inhibitory polypeptide in patients with type-2 diabetes mellitus. J Clin Invest 1993, 91:301-307.

4. Nauck MA, Wollschlager D, Werner J, Holst JJ, Orskov C, Creutzfeldt W, Willms B: Effects of subcutaneous glucagon-like peptide 1 (GLP-1 [7-36 amide]) in patients with NIDDM. Diabetologia 1996, 39:1546-1553.

5. Deacon CF: What do we know about the secretion and degradation of incretin hormones? Regul Peptides 2005, 128:117-124.
6. Nauck MA, Walberg J, Vethacke A, El-Ouaghlidi A, Senkal M, Holst JJ, Gallwitz B, Schmidt WE, Schmiegel W: Blood glucose control in healthy subject and patients receiving intravenous glucose infusion or total parenteral nutrition using glucagon-like peptide 1. Regul Peptides 2004, 118:89-97.

7. Meier JJ, Weyhe D, Michaely M, Senkal M, Zumtobel V, Nauck MA, Holst JJ, Schmidt WE, Gallwitz B: Intravenous glucagon-like peptide 1 normalizes blood glucose after major surgery in patients with type 2 diabetes. Crit Care Med 2004, 32:848-851.

8. Sokos GG, Bolukoglu H, German J, Hentosz T, Magovern GJ Jr, Maher TD, Dean DA, Bailey SH, Marrone G, Benckart DH, Elahi D, Shannon RP: Effect of glucagon-like peptide-1 (GLP-1) on glycemic control and left ventricular function in patients undergoing coronary artery bypass grafting. Am J Cardio/ 2007, 100:824-829.

9. Deane AM, Chapman MJ, Fraser RJ, Burgstad CM, Besanko LK, Horowitz M: The effect of exogenous glucagon-like peptide- 1 on the glycaemic response to small intestinal nutrient in the critically ill: a randomised double-blind placebo-controlled cross over study. Crit Care 2009, 13:R67.

10. Deane AM, Chapman MJ, Fraser RJ, Summers MJ, Zaknic AV, Storey JP, Jones KL, Rayner CK, Horowitz M: Effects of exogenous glucagon-like peptide-1 on gastric emptying and glucose absorption in the critically ill: relationship to glycemia. Crit Care Med 2010, 38:1261-1269.

11. Heine RJ, Van Gaal LF, Johns D, Mihm MJ, Widel MH, Brodows RG: Exenatide versus insulin glargine in patients with suboptimally controlled type 2 diabetes: a randomized trial. Annals Internal Med 2005, 143:559-569.

12. Kolterman OG, Buse JB, Fineman MS, Gaines E, Heintz S, Bicsak TA, Taylor K, Kim D, Aisporna M, Wang Y, Baron AD: Synthetic exendin-4 (exenatide) significantly reduces postprandial and fasting plasma glucose in subjects with type 2 diabetes. J Clin Endocrinol Metab 2003, 88:3082-3089.

13. Linnebjerg H, Park S, Kothare PA, Trautmann ME, Mace K, Fineman M, Wilding I, Nauck M, Horowitz M: Effect of exenatide on gastric emptying and relationship to postprandial glycemia in type 2 diabetes. Regul Peptides 2008, 151:123-129

14. Drucker DJ, Nauck MA: The incretin system: glucagon-like peptide-1 receptor agonists and dipeptidyl peptidase-4 inhibitors in type 2 diabetes. Lancet 2006, 368:1696-1705.

15. Deane A, Chapman MJ, Fraser RJ, Horowitz M: Bench-to-bedside review: The gut as an endocrine organ in the critically ill. Crit Care 2010, 14:228.

16. Finfer S, Chittock DR, Su SY, Blair D, Foster D, Dhingra V, Bellomo R, Cook D, Dodek P, Henderson WR, Hébert PC, Heritier S, Heyland DK, McArthur C, McDonald E, Mitchell I, Myburgh JA, Norton R, Potter J, Robinson BG, Ronco $\mathrm{J}$ : Intensive versus conventional glucose control in critically ill patients. NEngl J Med 2009, 360:1283-1297.

doi:10.1186/cc928

Cite this article as: Deane AM, et al.: The therapeutic potential of a venomous lizard: the use of glucagon-like peptide- 1 analogues in the critically ill. Critical Care 2010, 14:1004. 